\title{
Thermoacoustic-Stirling heat pump for domestic applications
}

\author{
Srinivas Vanapalli \\ M.E.H. Tijani \\ S. Spoelstra
}

Proceedings of ASME $20103^{\text {rd }}$ Joint US-European Fluids Engineering Summer Meeting and $8^{\text {th }}$ International Conference on Nanochannels, Mircochannels, and Minichannels, August 1-5, 2010, Montreal, Canada 


\section{Proceedings of ASME 2010 3rd Joint US-European Fluids Engineering Summer Meeting and 8th Inter- national Conference on Nanochannels, Microchannels, and Minichannels \\ FEDSM2010-ICNMM2010 \\ August 1-5, 2010, Montreal, Canada}

\section{FEDSM-ICNMM2010-31150}

\section{THERMOACOUSTIC-STIRLING HEAT PUMP FOR DOMESTIC APPLICATIONS}

\author{
Srinivas Vanapalli \\ Energy research Center of the Netherlands \\ 1755 ZG, Petten, The Netherlands
}

\author{
M. E. H. Tijani \\ Energy research Center of the Netherlands \\ 1755 ZG, Petten, The Netherlands
}

\author{
Simon Spoelstra \\ Energy research Center of the Netherlands \\ 1755 ZG, Petten, The Netherlands
}

\begin{abstract}
Domestic heating contributes to a significant amount of energy usage in the Netherlands. Due to scarce energy resources, attention to develop new and efficient technologies is increasing. At ECN, a burner driven heat pump employing thermoacoustic technology is being developed for possible applications in households and offices. The desired temperature lift is from $10{ }^{\circ} \mathrm{C}$ to $80{ }^{\circ} \mathrm{C}$. As a first step the heat pump is driven by a linear motor. Measurements and performance analysis of the heat pump are presented in this paper. The heat pump has a coefficient of performance which is the ratio of heat produced to the work input of 1.38 when operating between $10^{\circ} \mathrm{C}$ to $80{ }^{\circ} \mathrm{C}$. The performance relative to maximum possible Carnot value is $26.5 \%$.
\end{abstract}

\section{INTRODUCTION}

Efficient energy usage is the most important measure advocated for a sustainable energy future [1]. In the heat technology group at ECN, research is primarily carried out, to investigate and to develop thermal systems for household and industrial applications. Annually about 2107 PJ of final energy is consumed in the Netherlands excluding conversion losses and feedstock [2]. In the households and offices the energy usage in the form of heat is about 596 PJ. Typically gas burner boilers of various sizes are used for heating applications where the desired radiator temperature is about $80{ }^{\circ} \mathrm{C}$ for existing house holds and offices.
One of the more efficient ways to produce heat is to use a heat pump [3]. A heat pump is a machine that upgrades heat from a low temperature to a higher temperature consuming work. Figure 1(a) shows an illustration of a heat pump operating between ground source temperature of $10{ }^{\circ} \mathrm{C}$ and a radiator temperature of $80{ }^{\circ} \mathrm{C}$. This heat pump can be driven by an electrical motor. If an electrical motor is used to drive such a heat pump it will not lead to energy savings. This is elucidated from the following example. Let us assume that the COP of the heat pump (ratio of the heat produced to the work consumed) be about 2.5 (this value is about half of the theoretically maximum $\mathrm{COP}$ value for a heatpump operating between $10^{\circ} \mathrm{C}$ and $80^{\circ} \mathrm{C}$ ) and the efficiency of electricity production be about 0.4 (ratio of electrical to thermal energy). Neglecting losses in the electrical motor, the radiator heat produced is equal to the primary energy used to produce electricity. Hence electrically driven heat pump is not attractive from the energy savings perspective.

An alternative concept is a gas burner driven heat pump as illustrated in Figure 1(b). The burner drives an engine that produces mechanical work and heat at the radiator temperature. The mechanical work is used to drive a heat pump operating between ground source temperature (assumed here $10{ }^{\circ} \mathrm{C}$ ) and the radiator temperature. Let $\dot{Q}_{h, e}$ be the heat delivered by the burner to the engine. If we assume an engine efficiency of $30 \%$, then the energy produced at the radiator temperature $\dot{Q}_{m, e}$ is equal 
to $0.7 \dot{Q}_{h, e}$. If the heat pump has a COP of 2.0, the heat produced by the heat pump at radiator temperature is equal to $0.6 \dot{Q}_{h, e}$. So the total heat produced by the system at the radiator temperature is $1.3 \dot{Q}_{h, e}$. Hence we can have an en-

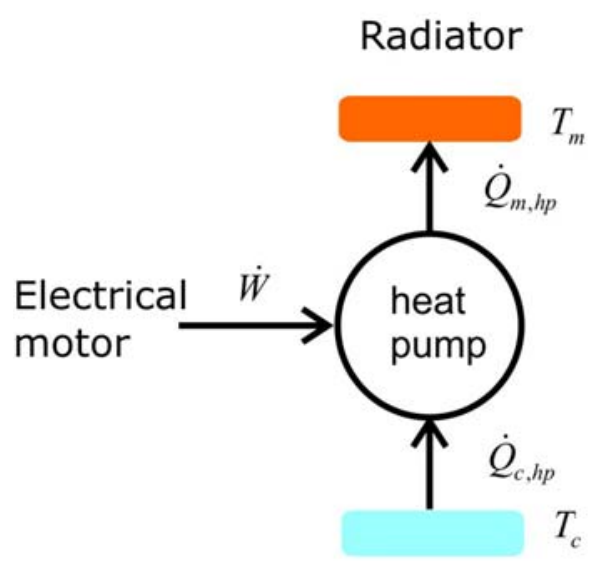

Ground source ergy savings of $30 \%$ of the high temperature source (primary energy).

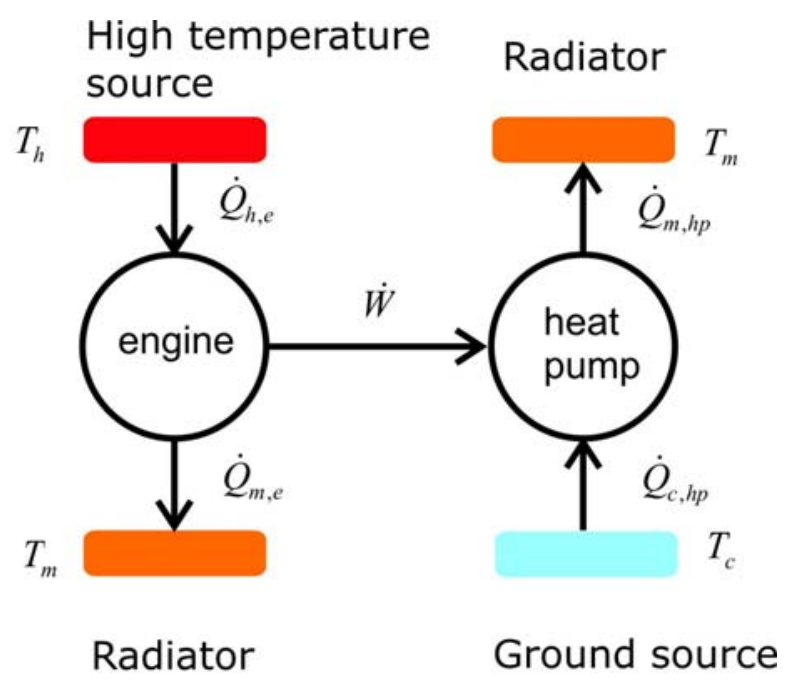

(b)

Figure 1. Illustration of a heat pump driven by an electrical motor (a) and a high temperature source such as a gas burner (b)

Such a burner driven heat pump is being investigated at ECN within the EU funded THATEA (THermoAcoustic Technology for Energy Applications) project. The project aims at advancing thermoacoustic technology to enable development of innovative and efficient heating and cooling systems. The performance targets in the project are $40 \%$ exergetic efficiency for the engine and the heat pump. In the first phase of the project, the engine and the heat pump are developed separately. The heat pump is driven by a pressure wave generator (linear motor). The aim of this study is to demonstrate the temperature lift of the heat pump and to meet the performance target. Previously a linear motor driven thermoacoustic-Stirling cooler was tested in our lab. In order to gain understanding of the dynamics of the heat pump the same cooler is tested under heat pump temperature conditions. In this paper, the description and the performance of the heat pump driven by a linear motor is presented.

\section{Heat pump terminology}

From the first law of thermodynamics, the sum of the work performed on the system $\dot{W}$ and the heat extracted $\dot{Q}_{c, h p}$ from the cold reservoir at the low tempera- ture $T_{c}$ is equal to the heat delivered to the hot reservoir $\dot{Q}_{m, h p}$ at the higher temperature $T_{m}$,

$$
\dot{Q}_{m, h p}=\dot{Q}_{c, h p}+\dot{W}
$$

The measure of the heat pump performance is the coefficient of performance $(C O P)$. For heating applications this is the ratio of heat rejected at high temperature to the work input

$$
C O P=\dot{Q}_{m, h p} / \dot{W}
$$

The upper theoretical value of COP obtainable in a heat pump is $C O P_{c}$ and is given by,

$$
C O P_{C}=T_{h} /\left(T_{h}-T_{c}\right)
$$

The ratio between the two COP values is the exegetic efficiency of the heat pump or sometimes called the performance relative to Carnot value $C O P_{r}$.

\section{Thermoacoustic-Stirling heat pump}


The working of a typical thermoacoustic-Stirling heat pump can be best understood by analyzing the classical Stirling cycle. The main components of a Stirling heat pump consist of a regenerator, warm and cold heat exchanger, and a power and displacer piston as shown in Figure 2 (a). Ideally, the only thermal interaction with the environment of such a system occurs at the two heat exchangers. The power piston is the location where the acoustic power is delivered into the heat pump. The displacer is used to feedback mechanical power to the power piston and also to maintain a good phase relationship between oscillating pressure and flow in the regenerator. A regenerator bridges the gap between the two heat exchangers. The gas exchanges heat with the regenerator material during a part of the cycle and that heat is given back to the gas in a later part of the cycle. In order to have good heat transfer between the gas and the solid material, the surface area for heat transfer should be large which is accomplished with the use of a highly porous and small gas passages (hydraulic diameter) regenerator

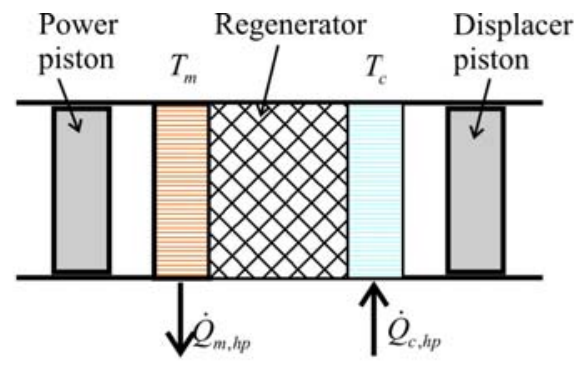

(a) Mechanical Stirling heat pump

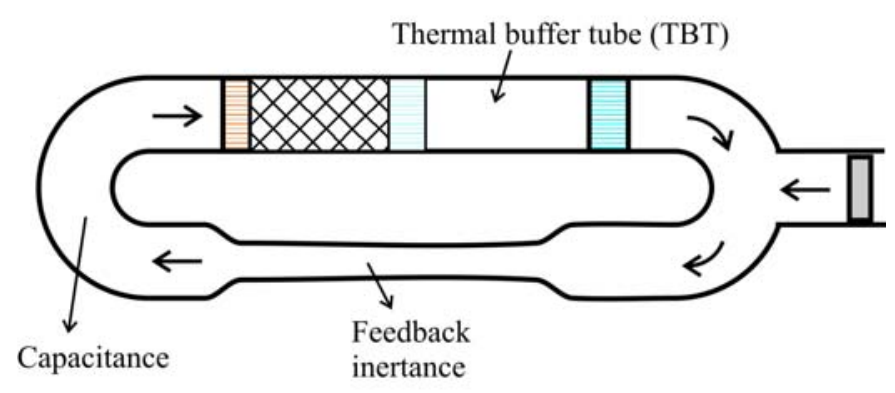

(b) Thermoacoustic Stirling heat pump

Figure 2.Classical Stirling heat pump (a) with power and displacer pistons. The temperatures and the heat flows at the heat exchangers are also shown. Thermoacoustic (TA) Stirling heat pump uses fluidic ducts to replace the functionality of the displacer piston. TA heat pump shown in (b) has a torus configuration. The arrows point in the direction of the acoustic power flow. material. In a thermoacoustic heat pump the functionality of the displacer piston is replaced by a combination of an inertance (fluidic inertia) and a capacitance (buffer volume) as shown in Figure 2(b). As in a mechanical Stirling heat pump, some of the acoustic power is fedback to the hot heat exchanger side of the regenerator via the feedback inertance. In contrast to the classical Stirling heat pump, thermoacoustic heat pump has fewer moving parts and hence is more reliable and cheaper to produce.

In thermoacoustic systems various performance parameters are expressed as a function of the drive ratio. The drive ratio $P_{1} / P_{0}$ is the ratio of dynamic pressure amplitude and the average pressure in the system.

\section{PROTYPE DESIGN \& CONSTUCTION}

\section{Pressure wave generator}

The pressure wave generator (PWG) is a twin piston moving magnet type of electrodynamic motor. The rated electrical power consumption is $210 \mathrm{~W}$. The piston diameter is about $70 \mathrm{~mm}$ and the maximum stroke is limited to $10 \mathrm{~mm}$ peak-to-peak. Provision is made in the moving mass of the motors to accommodate a displacer rod to measure piston displacement. Dynamic pressure sensors are mounted on the front and back side of the piston.

\section{Regenerator}

The regenerator is made of a stack of stainless steel wire mesh screens. The hydraulic radius of the screen is 30 $\mu \mathrm{m}$ and the porosity is about $75 \%$. The diameter and length of the regenerator is $60 \mathrm{~mm}$ and $25 \mathrm{~mm}$ respectively.

\section{Heat exchangers}

The heat exchangers are of gas-liquid type and are made of a stack of sandwiched plates which are brazed together. Copper fins are brazed on the helium gas side to increase the heat transfer area on the helium side. The diameter and length of the heat exchangers is 60 and $10 \mathrm{~mm}$ respectively.

\section{Feedback inertance}

The feedback inertance is made from a stainless tube of $27.86 \mathrm{~mm}$ nominal inside diameter. The length of the feedback along the centerline from the $\mathrm{T}$ junction to the buffer is $0.24 \mathrm{~m}$. 


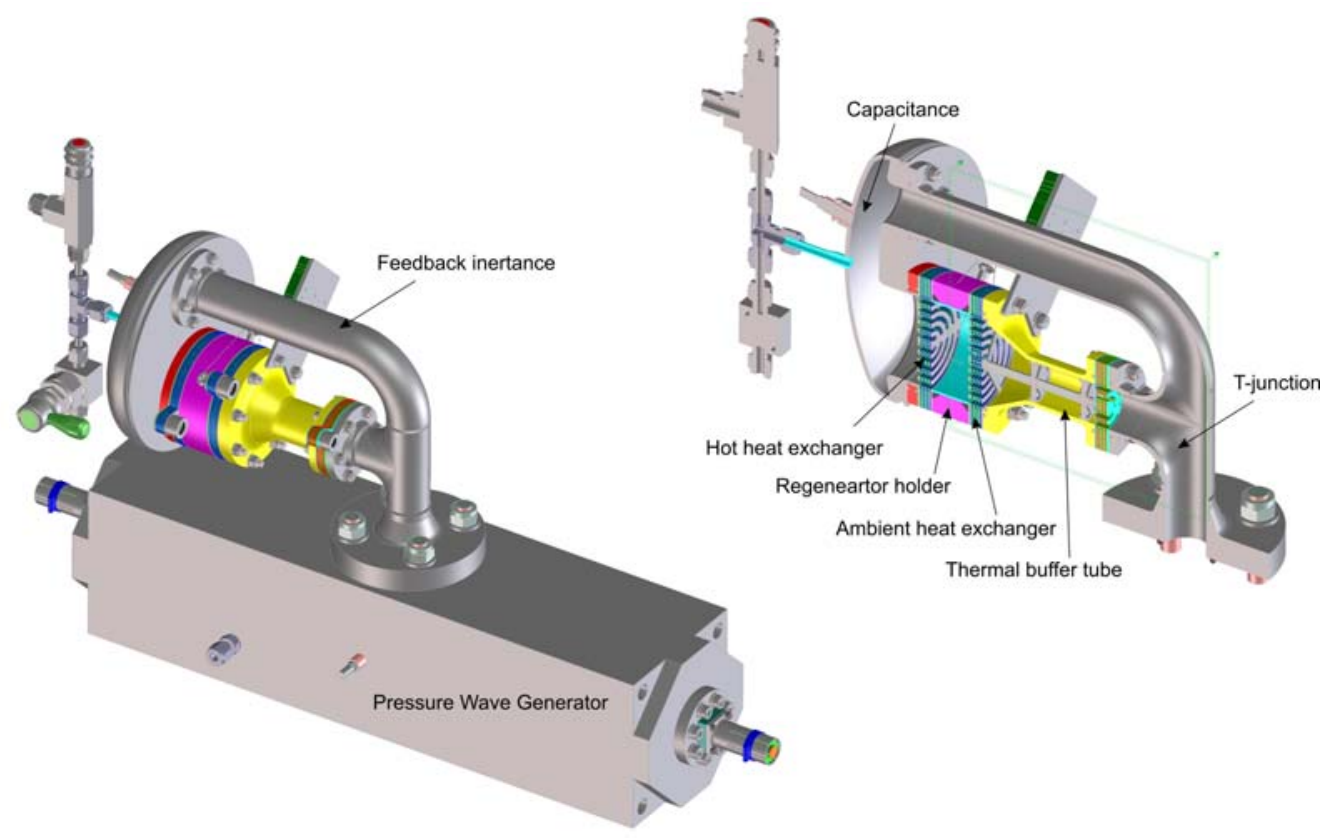

Figure 3. CAD model of the heat pump

\section{Model}

As described in the introduction section the apparatus shown in Figure 3 was originally designed for a cooler application. This system is modeled with DELTAEC code. Temperature conditions are modified in the model to match the experimental conditions of the heat pump. The segments in the heat pump model are as follows: From the junction of the pressure wave generator, a series of DUCT segments, model the interconnecting tubes. A TBRANCH segment branches into the feedback inertance. The feedback inertance is modeled as a duct followed by the VOLUME segment to model the capacitance. The heat exchangers and regenerator are modeled with HX and STKSCREEN segment models respectively. The thermal buffer tube is modeled with a STKDUCT segment. Finally the union of the branch with the trunk occurs at the location of the T-junction. Several MINOR segments model the acoustic losses in the circuit. It must be noted that we do not have good understanding of the minor losses. The COP calculated by the model for a cold temperature of $10{ }^{\circ} \mathrm{C}$ and a hot temperature of 80 ${ }^{\circ} \mathrm{C}$ is about $31.8 \%$ relative to Carnot.

\section{Test environment \& infrastructure}

Various sensors are mounted in the system to measure the operating parameters of the heat pump. The temperature in the regenerator is measured with a thermocouple at three different locations: one at the interface of the regenerator and the ambient heat exchanger, one in the middle of the regenerator and one at the interface of the regenerator and the hot heat exchanger. Dynamic pressure sensors are located at the capacitance, in the front and back of the pistons. LVDT's (Linear Variable Differential Transformer) mounted on the end caps of the PWG measure the displacement of the displacer rods connected to the piston. Water flow into the heat exchanger is measured with a turbine flow meter and the temperature of the water is measured with a thermocouple. The data is acquired using a Labview program.

The acoustic power produced by each piston is given by,

$$
\dot{W}=\frac{1}{2} P_{1} \dot{U}_{1} \cos \theta_{P U}
$$

where $P_{1}$ is the pressure amplitude and $\dot{U}_{1}$ is the volume flow rate at the face of the piston, $\theta_{P U}$ is the phase difference between pressure and volume flow rate. In the experiments, the displacement of the piston is measured using LVDT and not the velocity. The volume flow rate at the face of the piston expressed in relation to displacement is given by,

$$
\dot{U}_{1}=2 \pi f A s
$$


where $f$ is the frequency of operation, $A$ is the area of the face of the piston and $s$ is the stroke amplitude of the piston. The displacement of the piston lags $90^{\circ}$ from the velocity of the piston. So the phase difference between pressure and velocity leads the phase difference between pressure and displacement by $90^{\circ}$. Expressing equation 4 in terms of displacement of the piston becomes,

$$
\dot{W}=P_{1} \pi f A s \cos \left(\theta_{P s}+90^{\circ}\right) .
$$

The total acoustic power produced by the PWG is equal to the sum of the power produced by the two pistons.

Water is supplied to the heat exchangers from a temperature controlled bath. The thermal bath temperature is set to various temperature levels in the experiments. The thermal duty of the heat exchanger is calculated from the inlet $T_{\text {in }}$ and outlet temperature $T_{\text {out }}$ of the heat exchanger and the volume flow measurement $\dot{V}$ using the following formula,

$$
\dot{Q}=\rho \dot{V} c_{p}\left(T_{\text {in }}-T_{\text {out }}\right)
$$

where $c_{p}$ and $\rho$ are the specific heat capacity and density of water respectively.

\section{RESULTS \& DISCUSSION}

As mentioned in the introduction section, this setup is originally designed for cooler application. In the cooler, the hot heat exchanger operated at ambient temperature. This heat exchanger is attached to the capacitance through a flange. During the cooler design, thermal issues were not considered because the heat exchanger and the buffer are intended to remain at ambient temperature. In case of the heat pump, the hot heat exchanger should operate at a temperature above ambient temperature and as a consequence, significant amount of heat leaks from the heat exchanger to the flange and the capacitance. Since the aim of this study is to investigate the dynamic operation of the heat pump the static losses which cause a systematic error are eliminated as follows. Before starting a dynamic run (turning on the PWG), the thermal bath is set to the desired temperature and water is allowed to flow through the heat exchanger. 


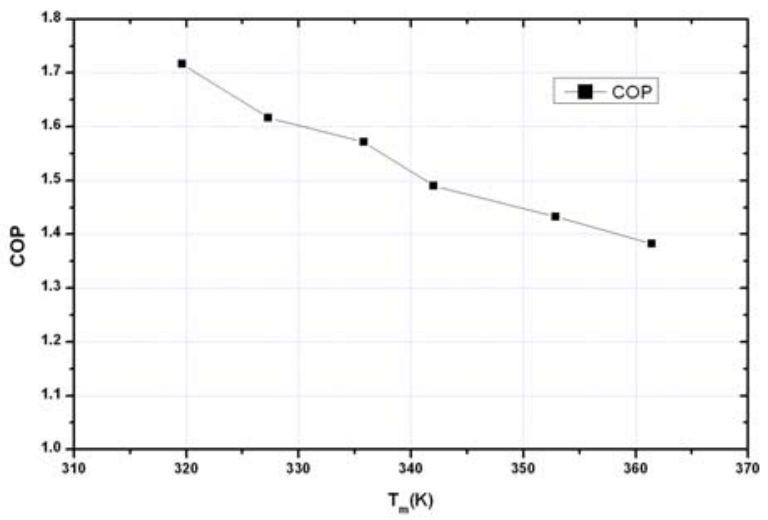

(a)

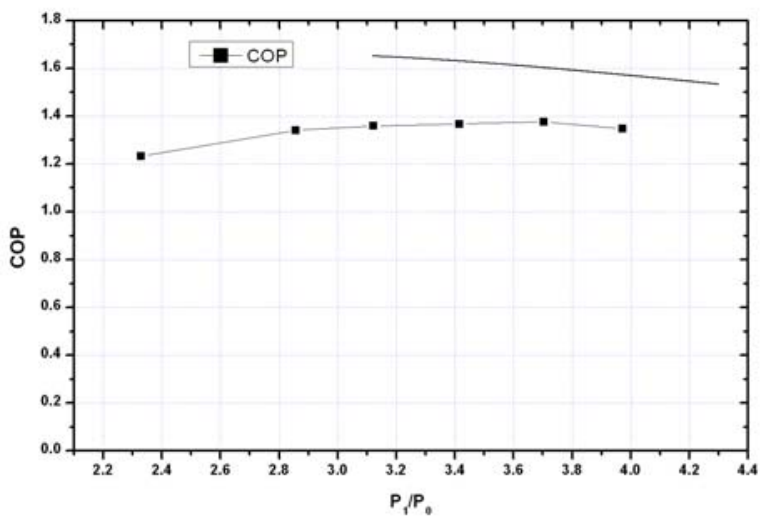

(c)

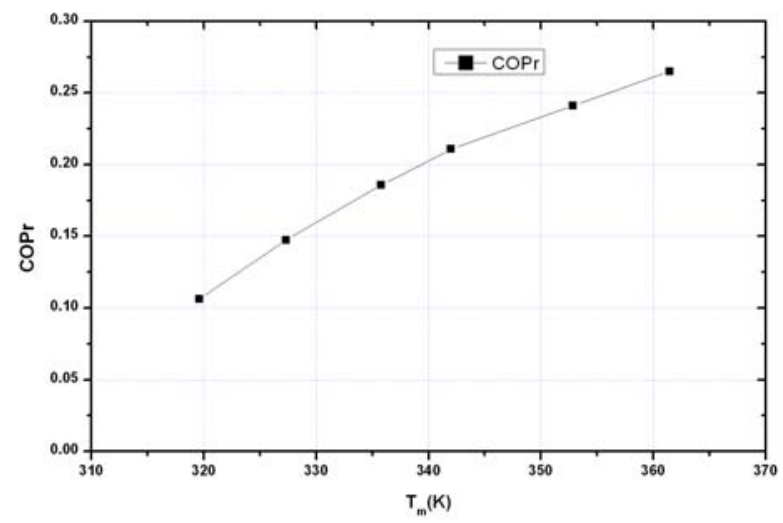

(b)

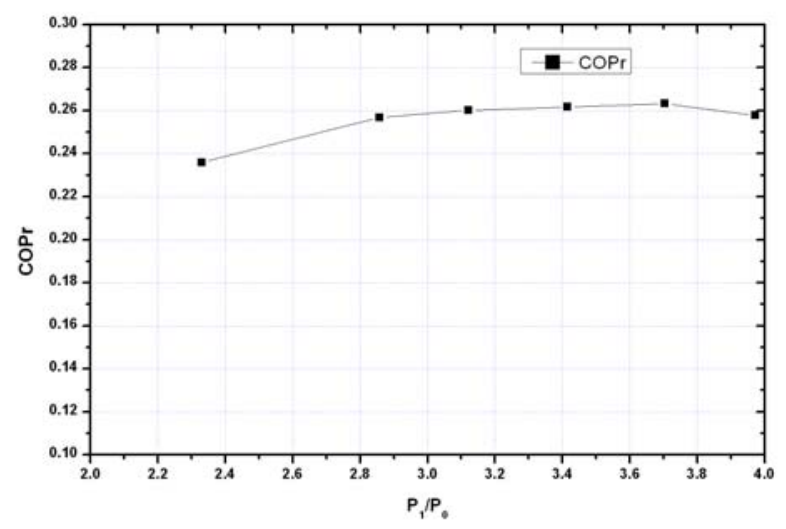

(d)

Figure 4. COP as function of hot temperature (a) and drive ratio (c). $C O P_{r}$ as a function of hot temperature (b) and drive ratio (d) These experiments were performed at a frequency of $98 \mathrm{~Hz}$ and an average pressure of $3.3 \mathrm{MPa}$. In (c) and (d) the inlet hot temperature of water is set to $80^{\circ} \mathrm{C}$.

The system is allowed to attain a steady state which is monitored by the thermocouples that measure inlet and outlet temperature of the water flow into the heat exchanger. In the Labview program the outlet thermocouple temperature is corrected to read the same temperature as the inlet thermocouple. This will ensure that the duty of the heat exchanger is zero under static conditions. Once this is done, the PWG is turned on and the data is acquired for the dynamic condition. This procedure is repeated for each different temperature run.

The average pressure in the system is $3.3 \mathrm{MPa}$ helium gas. The cold water flowing through the ambient heat exchanger is maintained at $10{ }^{\circ} \mathrm{C}$. Figure $4(\mathrm{a})$ and (b) shows the $C O P$ and $C O P r$ for several values of hot temperature respectively. The drive ratio $P_{1} / P_{0}$ is maintained equal to $3.7 \%$ by regulating the electrical voltage to the PWG. The maximum hot temperature in these experiments is limited to $85{ }^{\circ} \mathrm{C}$ because the medium used is water. The $\mathrm{COP}$ at the water inlet temperature of $80{ }^{\circ} \mathrm{C}$ is 1.38 and the COPr of the heat pump under these conditions is 0.26 . Figure 4(c) and (d) shows the COP and COPr of the heat pump for several values of drive ratio. In these plots, the hot water inlet temperature is maintained at $80^{\circ} \mathrm{C}$. Between drive ratios of 3.0 and $4.0 \%$ the COP of the heat pump does not vary much. It should be noted that a higher drive ratio gives a higher acoustic power input to the system and subsequently higher thermal powers. The model calculation with DELTAEC of the heat pump is also shown in Figure 4(c). The COP calculated by the model is slightly higher than the experiments. One of the reasons for this discrepancy is the lack of proper models to account for thermal and acoustic losses in the thermal buffer tube. The minor losses in the branches also need further investigation.

The following improvement measures are suggested for the heat pump. The heat leak from the hot heat exchanger to the capacitance is a major source of heat loss in the system. This can be minimized by placing a tube 
between the hot heat exchanger and the buffer. The heat leak from the hot heat exchanger to the cold heat exchanger via the tube wall is another source of heat leak which can be minimized by reducing the wall thickness of the regenerator holder. The thermal buffer tube in the current setup has a half taper angle of $28^{\circ}$. A more gradual (of about $7^{\circ}$ half angle) or no taper is preferred [5].

\section{CONCLUSIONS AND OUTLOOK}

Burner driven heat pumps that meet the heat demand of households and offices can lead to substantial energy savings compared to conventional gas boilers. Heat pumps based on thermoacoustic technology are attractive because they do not have any moving parts. A linear motor driven thermoacoustic heat pump produced a temperature lift of $70^{\circ} \mathrm{C}$ (operating between $10^{\circ} \mathrm{C}$ and 80 ${ }^{\circ} \mathrm{C}$ ). The maximum $\mathrm{COP}$ of the system at these conditions is $26 \%$ relative to Carnot value. The next stage of the development is focused on reducing the thermal and acoustic losses in the system. With these improvements we hope that the performance target of $40 \%$ relative to Carnot could be achieved.

\section{ACKNOWLEDGMENTS}

The THATEA project is partially funded by EU-FP7ENERGY program, grant number 226415.

\section{REFERENCES}

[1] Energy Technology Perspectives, Scenarios \& Strategies to 2050, International Energy Agency.

[2] Spoelstra, S., De Nederlandse en industriële energiehusihouding van 2000 tot en met 2006, ECN publication, 2006, www.ecn.nl/publicaties

[3] International Energy Agency, Heat Pump Center, www.heatpumpcentre.org.

[4] Clark, J. P., Ward, W. C., and Swift, G. W. Design environment for low-amplitude thermoacoustic energy conversion (DeletaEC)(A), J. Acoust. Soc. Am. Volume 122, Issue 5, pp. 3014, 2007.

[5] Olson, J. R. and Swift, G. W. Acoustic streaming in pulse tube refrigerators: Tapered pulse tubes. Cryogenics, 37:769776, 1997. 